\title{
Epidemiology of Oral Lichen Planus in a Cohort of South Indian Population: A Retrospective Study
}

\author{
Soma Susan Varghese', Giju Baby George ${ }^{2}$, Sreenivasan Bargavan Sarojini', Sankar Vinod ${ }^{3}$, Philips Mathew ${ }^{4}$, \\ Deepu George Mathew ${ }^{5}$, Joseph Sebastian ${ }^{6}$, Arun George ${ }^{6}$
}

${ }^{1}$ Department of Oral Pathology and Microbiology, ${ }^{2}$ Department of Oral Medicine and Radiology, ${ }^{3}$ Department of Oral and Maxillofacial Surgery, Mar Baselios Dental College and Hospital, Kothamangalam, ${ }^{4}$ Department of Oral Medicine and Radiology, Government Dental College, Kottayam, ${ }^{5}$ Department of Oral Pathology and Microbiology, ${ }^{6}$ Department of Oral and Maxillofacial Surgery, Mar Baselios Dental College, Kothamangalam, India

Background: Oral lichen planus (OLP) is an immune-mediated potentially malignant disorder of the oral cavity. Dysplastic OLP has an altered cytogenic profile and can progress into oral squamous cell carcinoma. The epidemiology of OLP is well-described in several relatively large series from various geographic locations, whereas such series from southern India is rare. The aim of the present study was to determine the epidemiology of OLP in a cohort of South Indian population.

Methods: All the case data records of 29,606 patients who visited Mar Baselios Dental College and Hospital, Kerala, India from 2014 to 2015 were retrospectively reviewed. For data review, 122 patients of OLP were selected Estimated were type, number, and location of lesions, clinical manifestation, age of the patient, gender, onset and duration of lesion, stressful life style, habits, skin involvement and associated systemic illness, and presence/absence of dysplasia.

Results: When the distribution of OLP among the gender was considered, we found more prevalence in females than males. Fifty-seven percent of patients were associated with stressful lifestyle. Reticular lichen planus was the most common clinical subtype found. Bilateral buccal mucosal was the common site, when the distribution of sites of OLP were compared $(P<0.05)$. Hypersensitivity reaction was frequently associated with systemic illness with $\operatorname{OLP}(P<0.05)$. Anaplasia was found among $5 \%$ of lichen planus lesions.

Conclusions: OLP patients had high incidence of hypersensitivity reactions and $5 \%$ of OLP lesions showed anaplasia. Long term follow-up is necessary to monitor the recurrence, prognosis, and malignant transformation of OLP.

(J Cancer Prev 2016;21:55-59)

Key Words: Lichen planus, Precancer, Immunologic diseases

\section{INTRODUCTION}

Lichen planus is an immune-mediated oral and cutaneous inflammatory disease, found in $0.5 \%$ to $2.6 \%$ of general population. ${ }^{1}$ The prevalence of oral lichen planus in Indian population is $2.6 \%$ with more female predilection. ${ }^{2}$ Oral lichen planus (OLP) is considered as a potentially malignant disorder with malignant transformation rate of $0.5 \%$ to $2 \%{ }^{3}$ It can involve as unilateral, bilateral, or multiple lesions. Skin lichen planus is the cutaneous counterpart of OLP affecting stratified squamous epithelium. Oral lesions are usually bilaterally distributed and appear as white streaks on erythematous areas. Buccal mucosa, tongue, and gingiva are the common sites affected by OLP. ${ }^{4}$ Skin lesions appear as pruritic flat-topped violaceous papules of ankles, wrist, and genitalia.

There are six recognized OPL planus: reticular, papular, plaque, atrophic, erosive, and vesiculo-bullous type. ${ }^{5}$ Reticular lichen planus (RLP) presents Wickham's striae with erythe-

Received February 11, 2016, Revised March 7, 2016, Accepted March 7, 2016

Correspondence to: Soma Susan Varghese

Department of Oral Pathology and Microbiology, Mar Baselios Dental College and Hospital, Kothamangalam 686691, Ernakulam district, Kerala State, India Tel: +91-0485-2828745, Fax: +91-0485-2828745, E-mail: drsomasusan@yahoo.in

Copyright (C) 2016 Korean Society of Cancer Prevention

(c) This is an Open Access article distributed under the terms of the Creative Commons Attribution Non-Commercial License (http://creativecommons.org/licenses/by-nc/4.0) which permits unrestricted non-commercial use, distribution, and reproduction in any medium, provided the original work is properly cited. 
matous margins. Erythematous lichen planus and atrophic lichen planus lesions exhibit erythematous back ground with radiating white striae. Plaque lichen planus appears as white plaque lesions whereas bullous lesions present as intraoral bullae. ${ }^{6}$

The exact aetiology of OLP is uncertain. Autoimmunity, immunodeficiency, food allergies, stress, habits, trauma, diabetes, and hypertension are considered as some of the etiological factors for lichen planus. ${ }^{7}$ Antigen-specific keratinocyte killing by CD8+ cytotoxic $\mathrm{T}$ cells, mast cell deregulation, and matrix metalloproteinase activation are some of the molecular pathogenesis behind lichen planus lesions. ${ }^{8}$

One of the most important complication concerning the progression and prognosis of OLP is the development of oral squamous cell carcinoma with a frequent malignant transformation of $0.5 \%$ to $2.0 \%$. World Health Organisation classified OLP as a potentially malignant disorder. ${ }^{9}$ Erosive and atrophic forms of lichen planus have high chance of malignant transformation. The aim of the present retrospective study is to determine the age and sex, clinical presentation, symptoms, systemic factors, the predisposing and aggravating factors, and the malignant potential of OLP.

\section{MATERIALS AND METHODS}

\section{Data collection}

All the case data records of 29,606 patients in the period 2014-2015 years from Mar Baselios Dental College and Hospital, Kerala, India were retrospectively reviewed. Patients with the clinical and pathological diagnosis of OLP were taken for the study. The diagnostic criteria proposed by Van der val classification of OLP were used to identify the cases of lichen planus. Based on these criteria, 122 patients with OLP were selected for data review. Type (reticular, erosive, bullous, and plaque), number, and location of lesions, clinical manifestation, age of the patient, gender, onset and duration of lesion, psychological factors, habits, skin involvement, and associated systemic illness were investigated.

Lichenoid lesions were excluded from the study. All the cases were confirmed with biopsy and histopathological examination. Histopathological criteria included parakeratosis, acanthosis, liquefaction degeneration of cells within basal layer, and subepithelial band of lymphocytes. This study was performed with authorization of scientific ethical committee Mar Baselios Dental College.

\section{Statistical analysis}

The data were subjected to statistical analysis and basic variation statistical values were calculated. Chi-square test and ANOVA was used for comparison at significance level $P<0.05$ with SPSS ver. 14 (SPSS Inc., Chicago, IL, USA).

\section{RESULTS}

When the distribution among the gender in 122 patients with OLP was considered, we found more prevalence in females $(n=$ 79) than males $(n=43)$. RLP was the most common form found and was present in 75 patients (61.5\%). Erosive form was present in 38 patients (31.1\%), while less number of plaque and bullous lichen planus lesions were present. All forms of lichen planus (reticular, erosive, plaque, and bullous) were prevalent in 30-60 years of both genders. The age distribution of gender is given in Table 1

Bilateral involvement of buccal mucosa was seen in 94 patients (77.0\%) with OLP, followed by tongue (Table 2). Out of these 94 patients of OLP with bilaterally involved buccal mucosa, 35 cases (37.2\%) showed involvement in other oral sites, tongue and gingiva. Out of 75 patients of RLP, 36 patients showed bilateral buccal mucosa involvement, 7 patients with right buccal mucosa involvement, and 18 with bilateral buccal mucosa collateral tongue. RLP on palate, gingiva, lips or the floor of the oral cavity was uncommon.

Out of 38 patients with erosive lichen planus, bilateral buccal mucosal involvement was seen in 22 patients (57.9\%). And bilateral buccal mucosa collateral tongue was found in 9 patients

Table 1. Age distribution of lichen planus in females and males

\begin{tabular}{lccc}
\hline \multirow{2}{*}{ Variable } & \multicolumn{3}{c}{ Age distribution (yr) } \\
\cline { 2 - 4 } & $15-30$ & $30-60$ & $>60$ \\
\hline Female $(\mathrm{n}=79)$ & 2 & 35 & 12 \\
Reticular & 3 & 16 & 6 \\
Erosive & - & 3 & - \\
Plaque & - & 2 & - \\
Bullous & 5 & 56 & 18 \\
Total & & & \\
Male $(\mathrm{n}=43)$ & 2 & 18 & 5 \\
Reticular & 1 & 7 & 5 \\
Erosive & - & 3 & 1 \\
Plaque & - & 1 & - \\
Bullous & 3 & 29 & 11 \\
Total & & & \\
\hline
\end{tabular}

Values are presented as the number of females or males with lichen planus. 
(23.7\%). Most of the patients with plaque and bullous lichen planus showed multifocal involvement. Cutaneous lichen planus was found in all the patients with bullous lichen planus (Table 2). A statistically significant difference was obtained with high incidence of bilateral buccal mucosal involvement when the distribution of sites of lichen planus was compared $(P<0.05)$ (Table 3).

Out of 122 cases of OLP, 61 patients (50.0\%) had burning sensation, $15 \%$ had the associated desquamative gingivitis, and 3 patients showed skin involvement. OLP patients with history of tobacco chewing, pan chewing, tobacco smoking, and alcoholism were reported in $8 \%, 4 \%, 5 \%$, and $5 \%$, respectively.

The incidence of systemic illness associated with lichen planus included hypertension, diabetes mellitus, hypersensitivity reactions (asthma, allergy, gastritis, and arthritis), hyperthyroidism, and skin vesiculobullous lesions (Table 4). About 71\% of OLP cases was associated with systemic illness. A statistically significant difference among all the group of lichen planus regarding the association of systemic illness was obtained ( $P=$ 0.002 ) with peak incidence of hypersensitivity reactions (Table 5).

Table 2. Single and multiple site involvement among various groups of lichen planus

\begin{tabular}{lrrrc}
\hline \multicolumn{1}{c}{ Site } & Reticular & Erosive Plaque & Bullous \\
\hline Bilateral buccal mucosa & 36 & 22 & - & 1 \\
Right buccal mucosa & 7 & 3 & - & - \\
Left buccal mucosa & 1 & 1 & - & - \\
Right buccal mucosa + tongue & 2 & 1 & 1 & - \\
Bilateral buccal mucosa + tongue & 18 & 9 & 3 & 2 \\
Bilateral buccal mucosa + gingiva & 2 & - & 1 & - \\
Right buccal mucosa + palate & 1 & - & - & - \\
Right buccal mucosa + floor of & 1 & - & - & - \\
$\quad$ mouth & & & & \\
Right buccal mucosa + lips & 1 & - & - & - \\
Palate & 1 & 1 & - & - \\
Tongue & 5 & 1 & - & - \\
Skin & - & - & - & 3 \\
\hline
\end{tabular}

Values are presented as number only.
In our study group, stress was occurred about $57 \%$ of lichen planus patients. Patients with erosive lichen planus showed the highest incidence of stress (31\%), compared with reticular (18\%), plaque (4\%), and bullous (3\%). Only $5 \%$ of cases of erosive lichen planus showed dysplastic features.

\section{DISCUSSION}

The present retrospective study aimed to elucidate the epidemiological and clinical characteristics as well as predisposing factors of OLP in a small cohort of southern Indian population. More prevalence in females than males was consistent with other studies. ${ }^{10}$ The peak age with OLP was found to be $30-60$ years for both males and females.

In the present study, RLP was the most common form, followed by erosive lichen planus. Cases with plaque and bullous were less frequent bilateral symmetrical involvement of buccal mucosa was evident in most patients with RLP and erosive lichen planus, followed by tongue as reported in other studies. ${ }^{11}$ Bilateral buccal mucosa concomitant with tongue was the common multiple site lesion in our study. Only $10 \%$ of cases showed unilateral buccal mucosal involvement. Most of the

Table 4. Systemic illness associated with lichen planus

\begin{tabular}{lcccc}
\hline \multicolumn{1}{c}{ Systemic illness } & Reticular & Erosive & Plaque & Bullous \\
\hline $\begin{array}{l}\text { Diabetes only } \\
\text { Diabetes and }\end{array}$ & 6 & 5 & - & - \\
hypertension & 5 & 3 & - & - \\
$\begin{array}{l}\text { Hypertension and asthma } \\
\text { Hypertension only }\end{array}$ & 4 & - & - & - \\
$\begin{array}{l}\text { Thyroid anomalies } \\
\text { Skin vesiculo bullous }\end{array}$ & 7 & 5 & 4 & - \\
$\quad \begin{array}{l}\text { lesions } \\
\text { Hypersensitivity reaction } \\
\text { only (asthma, allergy, } \\
\text { arthritis, gastritis) }\end{array}$ & 18 & 17 & 3 & 0 \\
\hline
\end{tabular}

Values are presented as number only among various groups of lichen planus lesion.

Table 3. Distribution of sites among various groups of lichen planus by chi-square analysis

\begin{tabular}{lrrrrr}
\hline \multicolumn{1}{c}{ Site } & \multicolumn{2}{c}{ Reticular } & Erosive & Plaque & Bullous \\
\hline Bilateral buccal mucosa & $36(35.98)(0.00)$ & $22(18.23)(0.78)$ & $0(1.92)(1.92)$ & $1(2.88)(1.23)$ \\
Bilateral buccal mucosa and other sites & $20(21.34)(0.08)$ & $9(10.81)(0.30)$ & $4(1.14)(7.20)$ & $2(1.71)(0.05)$ \\
Unilateral buccal mucosa & $8(7.32)(0.06)$ & $4(3.71)(0.02)$ & $0(0.39)(0.39)$ & $0(0.59)(0.59)$ \\
Unilateral buccal mucosa and other sites & $5(3.66)(0.49)$ & $1(1.85)(0.39)$ & $0(0.20)(0.20)$ & $0(0.29)(0.29)$ \\
Other sites & $6(6.71)(0.07)$ & $2(3.40)(0.58)$ & $0(0.36)(0.36)$ & $3(0.54)(11.31)$ \\
\hline
\end{tabular}

Chi-square statistics with $P<0.05$. The result is significantly presented as observed number (expected total number) and (chi-square statistics). 
Table 5. Association between systemic illness and lichen planus

\begin{tabular}{lrrrr}
\hline \multicolumn{1}{c}{ Systemic illness } & $\begin{array}{c}\text { No. of } \\
\text { subject }\end{array}$ & Mean $\pm \mathrm{SD}$ & F-value & $P$-value \\
\hline Diabetes & 11 & $2.80 \pm 3.20$ & 3.947 & 0.002 \\
Diabetes/hypertension & 8 & $2.00 \pm 2.45$ & & \\
Hypertension/asthma & 4 & $1.00 \pm 2.00$ & & \\
Hypertension & 17 & $4.25 \pm 3.30$ & & \\
Thyriodism & 7 & $1.75 \pm 3.50$ & & \\
Skin vesiculobullous & 3 & $0.75 \pm 1.50$ & & \\
$\begin{array}{l}\text { Hypersensitivity } \\
\text { reaction }\end{array}$ & 38 & $9.50 \pm 9.30$ & & \\
\hline
\end{tabular}

Values are presented in ANOVA statistics as number and mean \pm $\mathrm{SD}$.

patients with plaque and bullous lichen planus showed multifocal involvement. All the cases of bullous lichen planus showed skin involvement. Burning sensation was observed in patients in the form of pain and soreness as reported in other studies. ${ }^{12}$ Associated desquamative gingivitis was also observed in OLP patients. In addition, a few OLP patients had a habit of smoking or alcoholism. These habits could be linked with the development of lichen planus lesions. Lichen planus can be exasperated by heat and irritants from smoking and alcoholism. ${ }^{13}$

About $71 \%$ of OLP patients was found to be associated with systemic illness. In particular, peak incidence of hypersensitivity reactions are more associated with lichen planus, which was not evident in other studies. From this observation, we could present OLP as a counter part of hypersensitivity-mediated disease. Hypersensitivity reactions can induce molecular mimicry and epitope spreading. Molecular mimicry is one of the mechanisms by which an exogenous substance triggers an immune response against the host antigens. If the self antigen is structurally similar to the exposed foreign peptide, autoreactive Tlymphocyte can be activated, thereby destroying even the self antigen. ${ }^{14}$ In hypersensitivity-induced lichen planus lesions, the presence of pre-existing inflammation and foreign antigenic peptides which resemble MHC-derived peptides and self antigens can break immunological self tolerance when presented to $\mathrm{T}$ lymphocyte. This can lead to the development of a pathogen-specific immune response that cross-reacts with host structures, thereby causing tissue destruction. At the expense of hypersentivity reactions, in lichen planus lesions, along with exogenous antigenic peptides, the self antigenic peptides (basal cell keratinocytes) could be presented to $\mathrm{CD} 8+$ cytotoxic $\mathrm{T}$ cells by antigenic mimicry mechanism. Host antigenic determinants through tissue damage can also contribute to the development of self reactive $\mathrm{T}$ cell expansion known as epitope spreading. ${ }^{15}$ Damage in basal cell keratinocyte could result in epitope spreading in lichen planus lesions. Mast cell chymase was also found to be associated with the pathogenesis of OLP. ${ }^{16,17}$

Regarding the incidence of stress, about $57 \%$ of patients have reported history of stress with erosive lichen planus showing peak incidence. The majority of studies on this topic claim that stressful events proceeded lichen planus lesions and therefore might have resulted in anxiety, depression, and finally persisting lichen planus lesions. ${ }^{18}$

In the present study, only $5 \%$ of cases of erosive lichen planus showed dysplastic features. In contrast to non-dysplastic OLP dysplastic OLP has a distinct molecular profile and can progress into oral squamous cell carcinoma. Regular follow-up of OLP lesions with dysplastic changes are necessary.

In conclusion, OLP is a T cell mediated chronic inflammatory oral mucosal disease with high recurrence rate. The present study exemplified the epidemiological and clinical characteristics as well as predisposing factors of OLP in a small cohort of southern Indian population. Multiple site involvement is frequent with bilateral buccal mucosa being the common site of involvement. It is imperative to understand the pathogenesis of lichen planus for proper treatment. In the present study, we could find the association of OLP with stress, various systemic illnesses, particularly hypersensitivity reactions, and $5 \%$ of lichen planus lesions with malignant potential. Long term follow-up is necessary to monitor the recurrence, prognosis, and malignant transformation of OLP.

\section{CONFLICTS OF INTEREST}

No potential conflicts of interest were disclosed.

\section{REFERENCES}

1. Kanemitsu S. Oral lichen planus: malignant potential and diagnosis. Oral Sci Int 2014;11:1-7.

2. Murti PR, Daftary DK, Bhonsle RB, Gupta PC, Mehta FS, Pindborg JJ. Malignant potential of oral lichen planus: observations in 722 patients from India. J Oral Pathol 1986;15:71-7.

3. Mattsson U, Jontell M, Holmstrup P. Oral lichen planus and malignant transformation: is a recall of patients justified? Crit Rev Oral Biol Med 2002;13:390-6.

4. Sugerman PB, Savage NW. Oral lichen planus: causes, diagnosis and management. Aust Dent J 2002;47:290-7.

5. Andreasen JO. Oral lichen planus. 1. A clinical evaluation of 115 cases. Oral Surg Oral Med Oral Pathol 1968;25:31-42.

6. Mollaoglu N. Oral lichen planus: a review. $\mathrm{Br} J$ Oral Maxillofac Surg 2000;38:370-7.

7. Roopashree MR, Gondhalekar RV, Shashikanth MC, George J, 
Thippeswamy SH, Shukla A. Pathogenesis of oral lichen planus--a review. J Oral Pathol Med 2010;39:729-34.

8. Sugerman PB, Savage NW, Walsh LJ, Zhao ZZ, Zhou XJ, Khan A, et al. The pathogenesis of oral lichen planus. Crit Rev Oral Biol Med 2002; 13:350-65.

9. van der Waal I. Oral potentially malignant disorders: is malignant transformation predictable and preventable? Med Oral Patol Oral Cir Bucal 2014;19:e386-90.

10. Xue JL, Fan MW, Wang SZ, Chen XM, Li Y, Wang L. A clinical study of 674 patients with oral lichen planus in China. J Oral Pathol Med 2005:34:467-72.

11. Ingafou M, Leao JC, Porter SR, Scully C. Oral lichen planus: a retrospective study of 690 British patients. Oral Dis 2006;12:463-8.

12. Thongprasom K, Mravak-Stipetić M, Luckprom $\mathrm{P}$, Canjuga I, Biocina-Lukenda D, Vidović-Juras D, et al. Oral lichen planus: a retrospective comparative study between Thai and Croatian patients. Acta Dermatovenerol Croat 2009; 17:2-8

13. Meir G, Joel BE, Haya HK, Eliezer K. Smoking habits among patients diagnosed with oral lichen planus. Tob Induc Dis 2004:2:9.

14. Acharya S, Shukla S, Mahajan SN, Diwan SK. Molecular mimicry in human diseases: phenomena or epiphenomena? J Assoc Physicians India 2010;58:163-8.

15. Tchernev G, Orfanos CE. Antigen mimicry, epitope spreading and the pathogenesis of pemphigus. Tissue Antigens 2006;68:280-6.

16. Zhao ZZ, Sugerman PB, Zhou XJ, Walsh LJ, Savage NW. Mast cell degranulation and the role of $\mathrm{T}$ cell RANTES in oral lichen planus. Oral Dis 2001;7:246-51.

17. Zhao ZZ, Sugerman PB, Walsh LJ, Savage NW. Expression of RANTES and CCR1 in oral lichen planus and association with mast cell migration. J Oral Pathol Med 2002;31:158-62.

18. McCartan BE. Psychological factors associated with oral lichen planus. J Oral Pathol Med 1995;24:273-5. 